\title{
Molecular cloning and nucleotide sequence of another variant of the Escherichia coli Shiga-like toxin II family
}

\author{
Victor P. J. Gannon, ${ }^{1 *}$ Colleen Teerling, ${ }^{1}$ SaAd A. Masri ${ }^{1}$ and Carlton L. Gyles ${ }^{2}$ \\ ${ }^{1}$ Animal Diseases Research Institute, Agriculture Canada, PO Box 640, Gask Road, Lethbridge, Alberta, \\ Canada TIJ $3 Z 4$ \\ ${ }^{2}$ Department of Veterinary Microbiology and Immunology, Ontario Veterinary College, University of Guelph, Guelph, \\ Ontario, Canada N1G 2W1
}

(Received 29 September 1989; revised 11 January 1990; accepted 5 February 1990)

\begin{abstract}
Escherichia coli strain H.I.8 (O128: B12) produces low levels of a Shiga-like toxin (SLT) which we have called SLTIIva because of its close relationship with SLTIIv. The Vero cell cytotoxicity of SLTIIva is neutralized by antisera against SLTII and SLTIIv but not by antisera against SLTI. These data indicate that the SLT of strain H.I.8 is a member of the SLTII family. Since SLTIIva shares with SLTIIv the property of having low cytotoxicity to HeLa cells compared with Vero cells, it is appropriate to consider both toxins as variants of SLTII. SLTIIva differs from SLTIIv in that it is more heat-stable. Further, SLTIIv-producing strains of $E$. coli have only been isolated from pigs while the SLTIIva-producing $E$. coli strain examined in this study was isolated from a human infant with diarrhoea. The genes for this SLT were cloned from a cosmid library of total cellular DNA by screening recombinants for Vero cell toxicity and with a DNA probe derived from SLTIIv structural genes. Nucleotide sequence analysis was performed on a $2.0 \mathrm{~kb}$ AvaII-HincII fragment which encodes the toxin gene. The nucleotide sequence data confirm the close relationship between SLTIIva and SLTIIv: they have $98 \%$ nucleotide sequence homology in the B subunit gene and $70.6 \%$ homology in the A subunit gene. Comparison of DNA sequences indicated that SLTIIva was most closely related to SLTIIv, closely related to SLTII and less closely related to SLTI.
\end{abstract}

\section{Introduction}

Strains of Escherichia coli which produce Shiga-like toxins (SLTs) or Vero toxins (VTs) are associated with infant diarrhoea, haemorrhagic colitis and the haemolytic uraemic syndrome in man, dysentery in calves and oedema disease of pigs (Konowalchuk et al., 1977; O'Brien et al., 1982; Smith et al., 1983; Karmali et al., 1985; O'Brien \& Holmes, 1987; Smith \& Scotland, 1988). All SLTs have delayed Vero cell toxicity and share a common mechanism of action with Shiga toxin of Shigella dysenteriae type 1.

SLTs which have been well characterized include SLTI (O'Brien et al., 1982), SLTII (Strockbine et al., 1986; Jackson et al., 1987a), and a variant of SLTII (SLTIIv) which is produced by $E$. coli strains associated

Abbreviations: SLT, Shiga-like toxin; VT, Vero toxin.

The nucleotide sequence data reported in this paper have been submitted to GenBank and have been assigned the accession number M29153. with oedema disease (Marques et al., 1987; Weinstein et al., 1988; Gyles et al., 1988). SLTI is identical to Shiga toxin of Shigella dysenteriae type 1 in immunological cross-reactivity and biological activity and is nearly identical to this toxin in nucleotide and amino acid sequence (Jackson et al., 1987 b; Calderwood et al., 1987; De Grandis et al., 1987; Strockbine et al., 1988; Kozlov et al., 1988). SLTII and SLTIIv cross-react immunologically with each other and share $91 \%$ nucleotide sequence homology (Marques et al., 1987; Weinstein et al., 1988; Gyles et al., 1988). However, SLTII and SLTIIv are distinct from SLTI and Shiga toxin. SLTII and SLTIIv are not neutralized by polyclonal or monoclonal antisera generated against SLTI and Shiga toxin (Marques et al., 1987; Perera et al., 1988) and only share approximately $55-60 \%$ overall nucleotide sequence homology with the latter toxins (Newland et al., 1987; Weinstein et al., 1988; Gyles et al., 1988).

Other SLT or VT variants have been identified from E. coli $O$ serogroups 91,128 , and 157 based on differential cytotoxicity to Vero and HeLa cells (Karch \& 
Meyers, 1989; Oku et al., 1989; Gannon \& Gyles, 1990), reactions with conventional (Smith et al., 1987) and synthetic oligonucleotide probes (Karch \& Meyers, 1989; Brown et al., 1989), neutralization of toxicity with SLTspecific antisera (Dickie et al., 1989; Gannon \& Gyles, 1990) and analysis of antigenic components by the Ouchterlony double gel diffusion assay (Oku et al., 1989). Further, recent evidence (Dickie et al., 1989) suggests that VT2, first described by Scotland et al. (1985), is not identical to SLTII, described by Strockbine et al. (1986). In this study we report the cloning and nucleotide sequence analysis of an SLTII variant, which is different from the variant described previously (Marques et al., 1987; Weinstein et al., 1988; Gyles et al., 1988). The new toxin is designated SLTIIva, indicating that it is closely related to SLTIIv.

\section{Methods}

Bacterial strains and plasmids. SLT-producing E. coli strains examined are shown in Table 1. Plasmids and bacteriophages employed in the construction of the cosmid library, cloning, subcloning and DNA sequencing are shown in Table 2, as are the recombinant plasmids used in the study. E. coli K12 strains DH5 $\alpha$ (from BRL) and XL1-Blue (from Stratagene) were used as hosts in cloning and subcloning experiments. The $E$. coli $\mathrm{K} 12$ strain $\mathrm{C} 600 \lambda^{-}$, which originated from the late H. W. Smith (Houghton Poultry Research Station, Houghton, Cambridgeshire, UK), was used in the propagation of bacteriophages.

Media, enzymes, biochemicals and radionuclides. Luria broth (LB), or brain heart infusion broth or agar, were used for routine culturing of bacteria. Media were supplemented with X-Gal, IPTG and ampicillin for growth or selection of recombinants, as required. Restriction endonucleases, exonuclease III, S1 nuclease, T4 ligase, calf intestinal phosphatase, the Klenow enzyme and T4 kinase were purchased from BRL and T7 polymerase from Pharmacia. Radionuclides were purchased from Amersham.

Cloning, subcloning and restriction mapping. For small-scale preparation of plasmid DNA the alkaline lysis method of Birnboim \& Doly (1979) was used with modifications described by Morelle (1989); for large-scale plasmid preparation, either the Triton lysis method (Ausubel et al., 1987) or the rapid boiling procedure of Holmes \& Quigley (1981) was employed. In some experiments plasmid DNA was further purified by centrifugation in caesium chloride gradients. Total cellular DNA was isolated by the method of Ausubel et al. (1987) and procedures for cosmid cloning and in vitro packaging of ligated DNA were those of Maniatis et al. (1982). Methods described by Ausubel $e t$ al. (1987) were employed in the construction of the restriction map of insert DNA in pVGT10 (Fig. 1).

DNA hybridization studies. Plasmid DNA was transferred from agarose gels to nylon membranes (Hybond-N, Amersham) by a vacuum unit (VacuGene, Pharmacia-LKB) and total DNA to nylon membranes with a slot-blot apparatus (BioRad). Restriction fragments cloned into pUC19 or recovered from gel slices by electro-elution were denatured, mixed with random nucleotide hexamers and labelled with an equal mixture of $\left[\alpha^{-32} \mathrm{P}\right] \mathrm{dATP}$ and $\left[\alpha^{-32} \mathrm{P}\right] \mathrm{dCTP}\left(3000 \mathrm{Ci} \mathrm{mmol}{ }^{-1}\right.$; $110 \mathrm{TBq} \mathrm{m^{-1 }}{ }^{-1}$ using Klenow enzyme. Synthetic oligonucleotides

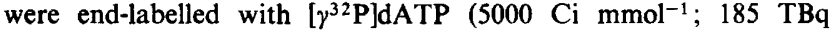
$\mathrm{mmol}^{-1}$ ) by $\mathrm{T} 4$ kinase. Highly stringent hybridization conditions were employed in all studies. For labelled DNA fragments the prehybridization and hybridization solutions consisted of $50 \%(\mathrm{v} / \mathrm{v})$ formamide, $5 \times$ SSC, $5 \times$ Denhardt's solution, $10 \%(\mathrm{w} / \mathrm{v})$ dextran sulphate, $0 \cdot 1 \%$ sodium dodecyl sulphate (SDS), with denatured salmon sperm at a concentration of $100 \mu \mathrm{g} \mathrm{ml}^{-1}$ [1 $\times$ Denhardt's solution is $0.02 \%$ bovine serum albumin, $0.02 \%$ Ficoll, $0.02 \%$ polyvinylpyrrolidone; $1 \times$ SSC is $0.15 \mathrm{M}-\mathrm{NaCl}, 0.015 \mathrm{M}$-trisodium citrate]. Membranes were preincubated in this solution for $2 \mathrm{~h}$ at $42^{\circ} \mathrm{C}$, labelled probe was added and membranes were incubated overnight at $42{ }^{\circ} \mathrm{C}$. After hybridization,

Table 1. SLT-producing E. coli strains

\begin{tabular}{lllll}
\hline \hline Strain & \multicolumn{1}{c}{ Disease } & \multicolumn{1}{c}{ Serotype } & SLT & \multicolumn{1}{c}{ Source or reference } \\
\hline H19 & Infant diarrhoea & O26:K60:H11 & SLTI & Konowalchuk et al. (1977) \\
C600 $(933 W)^{*}$ & None & SLTII & Strockbine et al. (1986) \\
E32511 & Haemolytic uraemic syndrome & O157:H- & 'VT2' & Scotland et al. (1985) \\
412 & Oedema disease & O139:K82 & SLTIIv & Gyles et al. (1988) \\
H.I.8 & Infant diarrhoea & O128:B12 & SLTIIva & Konowalchuk et al. (1977) \\
B2F1/3 & Haemolytic uraemic syndrome & O91:H21 & 'VT2' & Karmali et al. (1985) \\
\hline \hline
\end{tabular}

*An E. coli K12 C600 strain lysogenic for an SLT-converting bacteriophage from the E. coli O157:H7 strain 933.

Table 2. Plasmids and bacteriophages

\begin{tabular}{lll}
\hline \hline & \multicolumn{1}{c}{ Description } & \multicolumn{1}{c}{ Source and/or reference } \\
\hline pHC79 & Cosmid cloning vector & BRL; Hohn \& Collins (1980) \\
pUC18 and pUC19 & Cloning and sequencing vectors & BRL; Vieira \& Messing (1982) \\
M13 mp18 and mp19 & Sequencing vectors & BRL; Yanisch-Perron et al. (1985) \\
pCG6 & pUC18 with a 2.4 kb EcoRI-BgIII insert; sltIIv ${ }^{+}$ & Gyles et al. (1988) \\
pVGT5 & pHC79 with a 35 kb insert; sltIIva ${ }^{+}$ & This study \\
pVGT10 & pUC19 with a 4.5 kb HindIII insert; sltIIva ${ }^{+}$ & This study \\
pVGT15 & pUC19 with a $2 \cdot 0 \mathrm{~kb}$ AvaII-HincII insert; sltIIlva ${ }^{+}$ & This study \\
\hline \hline
\end{tabular}


membranes were given three 10 min washes with a solution of $2 \times$ SSC $/ 0.1 \%$ SDS at $42{ }^{\circ} \mathrm{C}$ and two $15 \mathrm{~min}$ washes with a solution of $0.1 \times$ $\mathrm{SSC} / 0.1 \% \mathrm{SDS}$ at $65^{\circ} \mathrm{C}$. Membranes for hybridization with oligonucleotide probes were prehybridized in $6 \times \mathrm{SSC}, 5 \times$ Denhardt's solution, $0.05 \%$ sodium pyrophosphate, $0.5 \%$ SDS, with denatured salmon sperm at a concentration of $100 \mu \mathrm{g} \mathrm{ml} l^{-1}$, for $1 \mathrm{~h}$ at $37^{\circ} \mathrm{C}$. Membranes were removed from the solution and placed in hybridization solution $(6 \times \mathrm{SSC} / 1 \% \mathrm{SDS})$ together with the labelled oligonucleotide probe and incubated overnight at $42^{\circ} \mathrm{C}$. After hybridization, membranes were washed three times in $6 \times \mathrm{SSC} / 1 \% \mathrm{SDS}$ for $10 \mathrm{~min}$ each wash and once for $5 \mathrm{~min}$ with $1 \times \mathrm{SSC} / 1 \% \mathrm{SDS}$ at $42{ }^{\circ} \mathrm{C}$. After washing, membranes were dried, covered with plastic wrap and exposed to X-ray film at $-70^{\circ} \mathrm{C}$.

Biological assays. Assays for cytotoxicity of bacterial culture supernatants in Vero (ATCC CCL 81) and HeLa 229 (ATCC CCL 2.1) cells, tests for neutralization of toxic activity with polyclonal porcine antisera and heat lability tests of toxins were performed as described by Gannon \& Gyles (1990). Polyclonal porcine antiserum to SLTIIv was obtained from D. L. MacLeod (Department of Veterinary Microbiology and Immunology, University of Guelph, Guelph, Ontario).

Bacteriophage induction. Induction of bacteriophages was accomplished by: (1) exposure of cultures to ultraviolet light as described by O'Brien et al. (1984); and (2) addition of mitomycin C (Sigma) to midexponential-phase cultures $\left(\mathrm{OD}_{600} 0.5\right)$ to a final concentration of $1 \mu \mathrm{g}$ $\mathrm{ml}^{-1}$ (Karch \& Bitzman, 1988).

Nicleotide sequence analysis. Restriction fragments of the $4.5 \mathrm{~kb}$ HindIII-HindIII insert (containing the slt gene) in recombinant plasmid pVGT10 (see Fig. 1), were subcloned into M13 mp18 and mp19 replicative-form vectors and into $\mathrm{pUC19}$ and pUC18 plasmids for single- and double-stranded DNA sequencing, respectively. For large DNA fragments where no convenient restriction sites could be located, deletions of DNA were created by exonuclease III digestion (Henikoff, 1984). Either a 17-base M13 universal primer or synthetic 17-mer oligonucleotides complementary to the insert DNA (Regional DNA Synthesis Laboratory, Calgary, Alberta, Canada) were used as primers for the dideoxy chain-termination method of sequence analysis (Sanger et al., 1977). T7 DNA polymerase was substituted for the Klenow enzyme in sequencing reactions. The DNA sequence was determined for both strands. For areas where GC compression was noted, 7-deaza-dGTP (US Biochemicals) was used in place of dGTP in chain-termination reactions. The MicroGenie computer program, version 6.0 (Beckman Instruments) was used to analyse and compare the sitIIva sequence data with those of other slt genes and the predicted amino acid sequence of the SLTIIva A subunit with that of the ricin A chain. Homology comparisons among SLT genes were made using the alignment function of the MicroGenie program. Nucleotide or predicted amino acid sequences of SLT A and B subunits, extending from the proposed signal peptide cleavage site or the $\mathrm{N}$-terminus of the mature polypeptide to the termination codon or C-terminus of the polypeptide, were compared. In the promoter region comparisons are based on optimal sequence alignment of nucleotides $5^{\prime}$ to the initiation codon of the A subunit sequence. The nucleotide sequence $3^{\prime}$ to the termination codon of the B subunit was compared in the same manner. In certain cases gaps were introduced into nucleotide or amino acid sequences by the computer program to achieve optimal alignment.

\section{Results}

\section{Cloning of the sltIIva genes}

VT assays on the broth culture supernatants from 600 recombinants obtained from the cosmid library of $E$. coli strain H.I. 8 yielded two positive clones. A $1.065 \mathrm{~kb}$ fragment of the sltIIv gene (from pCG6), which extends from the $E c o \mathrm{RV}$ site in the A subunit gene to the PstI site in the B subunit gene (Weinstein et al., 1988; Gyles et al., 1988), was used as a DNA probe. This probe hybridized with a $4.5 \mathrm{~kb}$ fragment from HindIII-digested cosmid DNA of the $\mathrm{VT}^{+}$clones. The $4.5 \mathrm{~kb}$ HindIII fragment of one of the $\mathrm{VT}^{+}$cosmid clones, pVGT5, was subcloned into pUC19 to yield the recombinant plasmid pVGT10. A restriction map of pVGT10 insert DNA is presented in Fig. 1.

To determine the extent of the sltIIva genes, various restriction fragments of insert DNA from pVGT10 were subcloned into pUC19 and used to transform $E$. coli strain DH5 $\alpha$, and the culture supernatants of these transformants were tested in the VT assay. A $2 \cdot 0 \mathrm{~kb}$ region of pVGT10 insert DNA bounded by AvaII and HinclI sites, respectively, was found necessary for VT activity. This DNA fragment was subcloned into pUC19, as described in Fig. 1, to yield pVGT15.

\section{Characteristics of VT produced by recombinant E. coli strains}

VT in the culture supernatants of the cosmid clone DH $5 \alpha(\mathrm{pVGT} 5)$ and in DH5 $\alpha$ (pVGT10) and DH $5 \alpha$ (pVGT15) was identical to that of strain H.I. 8, in that: (1) it was partially neutralized by polyclonal porcine antisera to SLTIIv and SLTII, but was not neutralized by anti-SLTI (Table 3); (2) VT activity was retained after heating at $80^{\circ} \mathrm{C}$ for $30 \mathrm{~min}$; and (3) titres in cytotoxicity assays were similar to SLTIIv preparations from $E$. coli 412 , in that they were approximately 125-fold greater in Vero than in HeLa 229 cells. Titres in cytotoxicity assays for broth culture supernatants from $E$. coli strains H19(SLTI) and C600(933W)(SLTII) in contrast, were approximately equal in these two cell lines.

\section{Location of sltIIva genes in E. coli strain H.I.8}

Repeated attempts to induce bacteriophages from broth culture supernatants of $E$. coli strain H.I. 8 by exposure of cultures to ultraviolet light, or by culture in the presence of mitomycin C, were unsuccessful. In contrast, bacteriophages were readily induced from $E$. coli strains $\mathrm{H} 19$ and $\mathrm{C} 600(933 \mathrm{~W})$, and C600 lysogens obtained from plaques for these two strains were $\mathrm{VT}^{+}$.

To determine the cellular location of sltIIva genes, a $770 \mathrm{bp} P s t \mathrm{I}-B g / \mathrm{II}$ fragment internal to the cloned slt IIVa structural genes (see Fig. 1) was obtained from pVGT15 and used as a probe in DNA hybridization studies with plasmid and total cellular DNA of E. coli strain H.I.8. 


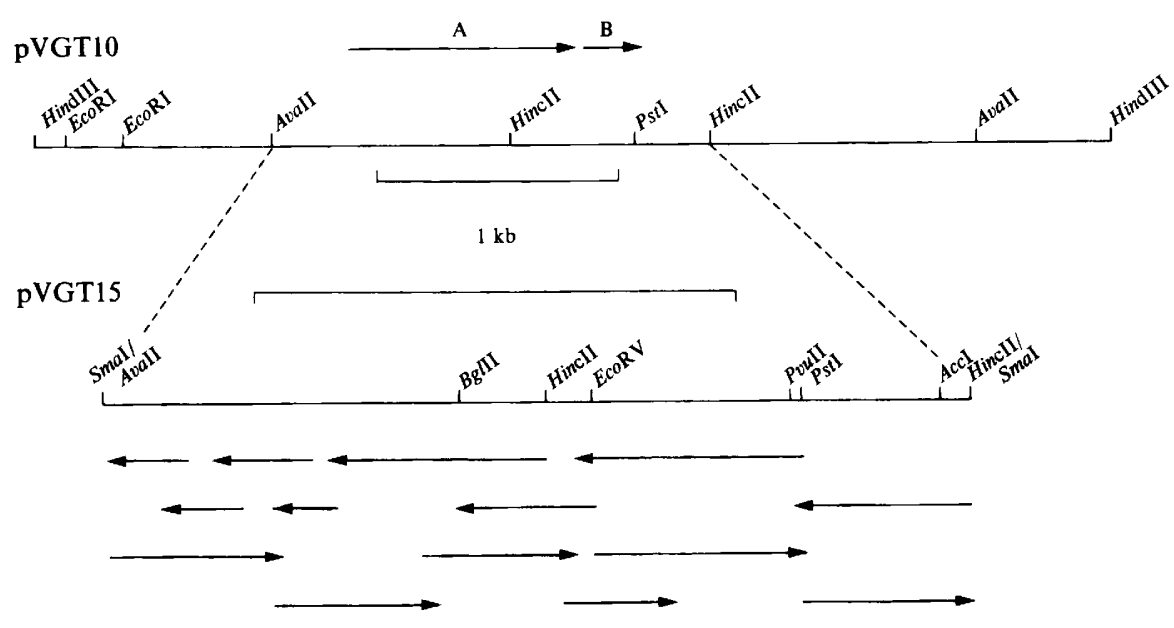

Fig. 1. Restriction enzyme map of a DNA fragment encoding SLTIIva. A $4.5 \mathrm{~kb}$ HindIII-HindIII fragment obtained from a VT ${ }^{+}$ cosmid clone of $E$. coli strain H.I.8, pVGT5, was subcloned into pUC19 to give the recombinant plasmid pVGT10. VT activity was determined for $E$. coli $\mathrm{DH} 5 \alpha$ transformants of recombinant plasmids which contained various restriction fragments of pVGT10. Based on this analysis a $2.0 \mathrm{~kb}$ AvalI-HincII region of DNA necessary for VT activity was identified. This region was subcloned as follows. (1) The left $3.1 \mathrm{~kb}$ HindIII-Pst and adjacent $200 \mathrm{bp}$ Pst $\mathrm{I}-$ HincII fragments were sequentially subcloned into pUC19 to reconstitute the left $3.3 \mathrm{~kb}$ HindIII-HincII region (in this construct, pVGT12, insert DNA was bounded by a HindIII site and a HincII/SmaI junction), (2) pVGT12 was then digested with AvalI (since the insert contains one and pUC19 contains two AvalI sites, three DNA fragments were generated). (3) Fragments were made blunt-ended by $S 1$ nuclease digestion and filling with the Klenow enzyme. (4) The DNA was then digested with $S s t$, which freed the $2.0 \mathrm{~kb}$ fragment of interest from pUC19 DNA (SstI cleaved in the multiple cloning site near the $H$ incII/SmaI junction). The $2.0 \mathrm{~kb}$ fragment was isolated from an agarose gel and ligated to pUC19, which had been digested with $S m a \mathrm{I}$ and SstI. This yielded the recombinant pVGT15, which has insert DNA bounded on one side by a SmaI/AvaII junction and on the other by a HincII/SmaI junction. The location and orientation of the structural genes for the SLTIIva A and B subunits are shown above the map. Arrows below the map indicate the direction and extent of DNA sequence analysis.

Table 3. Neutralization of VT in E. coli broth culture supernatants by porcine polyclonal antisera

\begin{tabular}{lrcr}
\hline \hline & \multicolumn{3}{c}{ Neutralization titre*, with antiserum ${ }^{+}$} \\
& against: \\
\cline { 2 - 4 } E. coli strain & SLTI & SLTIIv & SLTII \\
\hline H.1.8 & 0 & 625 & 25 \\
DH5 $\alpha$ (pVGT15) & 0 & 625 & 25 \\
412 & 0 & $\mathbf{3 1 2 5}$ & 125 \\
H19 & $\mathbf{3 1 2 5}$ & 0 & 0 \\
C600(933W) & 0 & 25 & $\mathbf{3 1 2 5}$ \\
\hline \hline
\end{tabular}

* The titre is the reciprocal of the highest dilution of serum which completely neutralized the effects of $10 \mathrm{CD}_{50}(\mathrm{CD}$, cytotoxic dose) of SLT preparations. Titres against the homologous type of SLT are shown in bold type.

† Antisera were prepared in pigs with purified SLTI and SLTIIv preparations and formalin-treated cultures of E. coli C600(933W) (SLTII ${ }^{+}$.

The probe hybridized with a single band from HindIII digests of total DNA, corresponding in size to the $4.5 \mathrm{~kb}$ HindIII insert of pVTG10, but did not hybridize with HindIII-digested plasmid DNA from this E. coli strain (see Fig. 2).

\section{Nucleotide sequence analysis}

The nucleotide sequence of the slt genes presented in Fig. 3 begins approximately 200 bases downstream of the AvaII/SmaI junction of pVGT15 and extends to the 3 end of the insert. Two open reading frames corresponding to the genes encoding the $\mathrm{A}$ and $\mathrm{B}$ subunits were located within this DNA fragment. Homology to the published DNA sequences and the predicted amino acid sequences of SLTs (Calderwood et al., 1987; De Grandis et al., 1987; Jackson et al., 1987a; Weinstein et al., 1988; Gyles et al., 1988) is summarized in Table 4. The DNA sequence of the B subunit gene had the closest relationship ( $98 \%$ ) to the B subunit region of slt IIv while the A subunit gene had a similar level of homology to the A subunit genes of $s l t \mathrm{IIV}(70.6 \%)$ and $s l t \mathrm{II}(69.5 \%)$. slt I had the least DNA sequence homology in both A and B subunit genes (58.8 and $64.3 \%$, respectively).

A putative promoter was identified upstream of the A subunit initiation codon, with -35 and -10 regions with homology to the consensus hexamers of McClure (1985) (see Fig. 3). The putative promoter region of sltIIva had low homology to the corresponding regions of other slt operons (from $38.3 \%$ for slt II to $39.6 \%$ for $s l t \mathrm{I}$ ).

Putative ribosome-binding sites (Shine \& Dalgarno, 


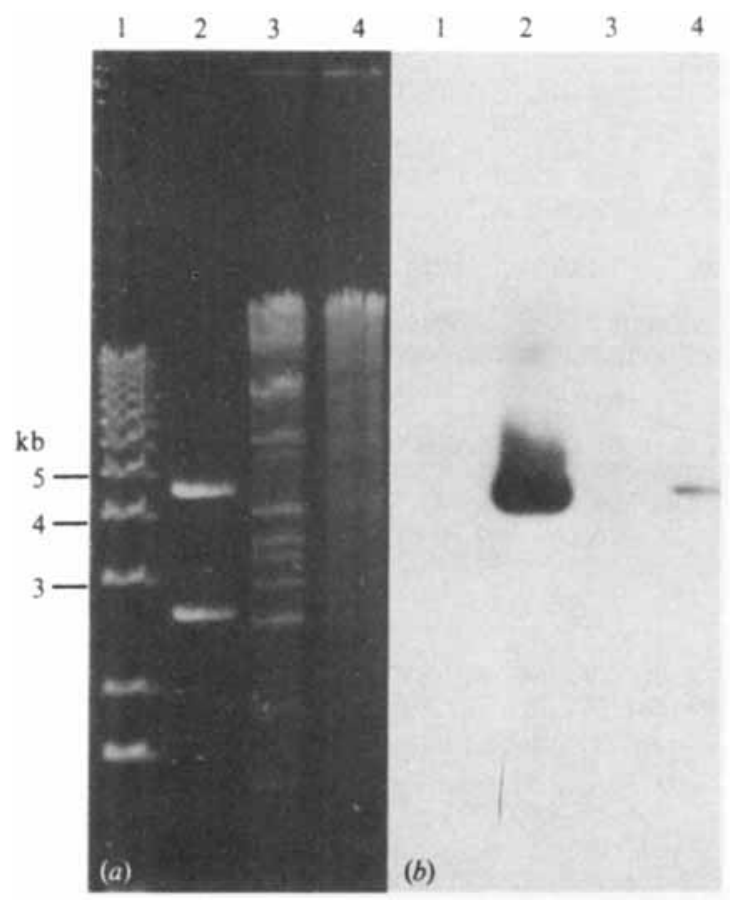

Fig. 2. Hybridization experiments with HindIII-digested plasmid and total cellular DNA of E. coli strain H.I.8. Photograph $(a)$ is of a $0.8 \%$ agarose gel with DNA samples stained with ethidium bromide; photograph $(b)$ is of an autoradiograph of a membrane following hybridization of transferred DNA samples with a ${ }^{32} \mathrm{P}$-labelled $770 \mathrm{bp}$ $B g l I I-P s t I$ fragment from pVGT15. Lanes: 1, molecular mass markers; 2, HindIll-digested pVGT10 DNA; 3, caesium-chloride-purified plasmid DNA from E. coli H.I.8 digested with HindIII; 4, total DNA from $E$. coli H.I. 8 digested with HindIII.

1974) for regions encoding the A and B subunits, respectively, are shown in Fig. 3. One of these occurs in the 15 nucleotide gap between the A and B subunits of slt IIva. The same number of nucleotides is present in the space between A and B subunit genes in the sltIIv operon (Weinstein et al., 1988).

The region $3^{\prime}$ to the termination codon of the B subunit of sltIIva contains two regions highly homologous to the slt IIV sequence. The first includes a stretch of 82 nucleotides following the termination codon of the $\mathrm{B}$ subunit. This area of homology is interrupted by 38 nucleotides not found in sltIIv. Following this insertion another region of 119 nucleotides with high homology to slt IIv is present. Overall homology of the region sequenced $3^{\prime}$ to the end of the B subunit was $74 \%$ for sltIIv as compared to $44.5 \%$ and $47 \%$ homology for $s l t \mathrm{I}$ and sltII, respectively. Similar regions of high homology were not observed in the latter gene sequences.

A stretch of DNA with several features of a rhoindependent termination signal (Brendel \& Trifonov, 1984) was found downstream of the B subunit gene (see Fig. 3). These features include a GC-rich region in the $3^{\prime}$ portion, a region of dyad symmetry with a high predicted free energy $\left(-17.4 \mathrm{kcal} \mathrm{mol}^{-1} ;-72.8 \mathrm{~kJ} \mathrm{~mol}^{-1}\right)$ for the 8 base stem structure, a T-rich stretch and the sequence TCTG at the $5^{\prime}$ end of the region. However, the single nucleotide of the 'loop' and the absence of $G$ nucleotides on the $3^{\prime}$ side of the stem is somewhat anomalous.

Putative signal sequences (von Heijne, 1984, 1985) for A and B subunits were identified (Fig. 3) 22 and 19 amino acids from the $\mathrm{N}$-terminus of the respective subunit polypeptides. Based on these data the processed A subunit consists of 297 amino acid residues and has a molecular mass of $33091 \mathrm{Da}$, while the processed B subunit consists of 68 amino acids and has a molecular mass of $7556 \mathrm{Da}$. SLTIIv is thought to contain the same number of amino acids in the respective processed $A$ and B subunits (Weinstein et al., 1988). A site susceptible to cleavage by trypsin was identified in the A polypeptide chain (position 250) which is bounded on each side by a cysteine residue. Tryptic cleavage could, therefore, result in the generation of $\mathrm{A} 1$ and $\mathrm{A} 2$ fragments.

\section{The relationship of sltIIva to other slt genes}

Three 17-base regions of the sltIIva A subunit sequence, one each in the $5^{\prime}$ end, middle portion and $3^{\prime}$ end, were selected at random to examine the relationship of the

Table 4. Homology comparison of the nucleotide and predicted amino acid sequence of the processed $A$ and $B$ subunits of the sltIIva genes

Homology is expressed as the percentage relatedness of sequences obtained using the ALIGN function of the MicroGenie computer program.

\begin{tabular}{lccccc}
\hline \hline & \multicolumn{2}{c}{ Nucleotide sequence } & & \multicolumn{2}{c}{ Amino acid sequence } \\
\cline { 2 - 3 } \cline { 6 - 6 } & A subunit & B subunit & & A subunit & B subunit \\
\hline SLTIIv & $70 \cdot 6$ & $98 \cdot 0$ & & $72 \cdot 4$ & $97 \cdot 1$ \\
SLTII & $69 \cdot 5$ & $78 \cdot 1$ & & $71 \cdot 4$ & $84 \cdot 3$ \\
SLTI & 58.8 & $64 \cdot 3$ & & $56 \cdot 2$ & 62.3 \\
\hline \hline
\end{tabular}


$\begin{array}{lccccccc}0 & 20 & 30 & 40 & 50 & 60 & 70 & 80 \\ & + \text { t }+++ \text { GA G C CG C } & \text { AC GGGT G TGGT CGGGG } & \text { CG GTCC } & \text { +G TGGCGG } & \text { ATT T }\end{array}$ ATATGTGAGAGATTCTCTATTCTATAAAATATAAACCATATACCCGTAATCTTAAATAATTGATACTATTTTCCGGAAG

$\begin{array}{llllllll}90 & 100 & 110 & 120 & 130 & 140 & 150 & 160\end{array}$ GC + CATG G G TA CAG CGGA A GC TT CCTTC GCA C GT C GG CGAATCC TAC A CTATAGTGCATCATTATCTGCTTTCTGTTCCTGATAAACAGGGAAGTAATACATTGTGCAGTCATTTCCTGTGAGGGGAT

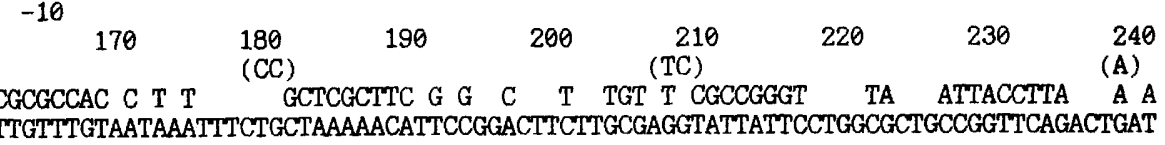
A A 250
260
270
280
290
TG A A C G C G TA C G 300

GGAGTGTTAATAT ATG CGA CAT ATA TTA TTA AAG CTG GTG TTG TTT TTT TGT GTT TGC TTG TCT

SD Met Arg His Ile Leu Leu Lys Leu Val Leu Phe Phe Cys Val Cys Leu Ser $-22$ Lys Cys Trp Ile Cys Leu Leu Leu Gly Phe

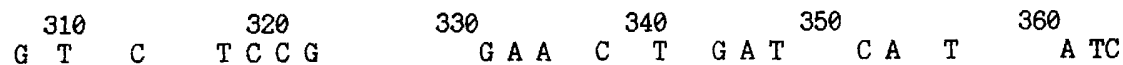
TCA GCA TCT TAT GCA GAT GAG TTT ACT GTG GAT TTC TCT TCG CAA AAG AGC TAT GTT GAT Ser Ala Ser Tyr Ala Asp Glu Phe Thr Val Asp Phe Ser Ser Gln Lys Ser Tyr Val Asp Val Ser Gln $\quad$ Ile Thr Gln $-1+1$ 10

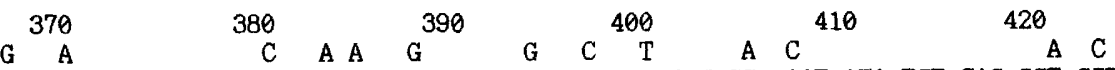
TCA TTG AAT AGT ATA AGG TCG GCA ATA TCC ACT CCA CTT GGA AAT ATA TCT CAG GGT GGT Ser Leu Asn Ser Ile Arg Ser Ala Ile Ser Thr Pro Leu Gly Asn Ile Ser Gln Gly Gly 20 Thr Glu His Ala

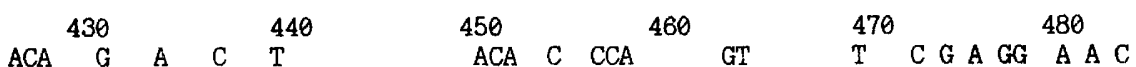
GTT TCT GTT TCA GTA ATT AAT CAT GTT CTA GGC GGA AAC TAT ATA TCA TTG AAT GTT AGA Val Ser Val Ser Val Ile Asn His Val Leu Gly Gly Asn Tyr Ile Ser Leu Asn Val Arg Thr

40 Thr Pro Pro Ser Val Gly Ile

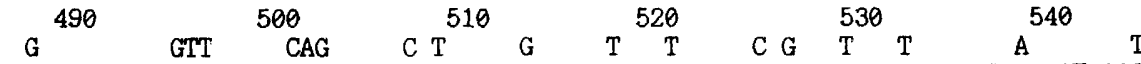
GGC CTT GAT CCA TAT AGC GAG AGA TTT AAC CAC CTC CGT TTA ATA ATG GAA CGG AAT AAC Gly Leu Asp fro Tyr Ser Glu Arg Phe Asn His Leu Arg Leu Ile Met Glu Arg Asn Asn

60

550

TTA TAT GTT GCA GGC TTT ATT AAT ACT GAA ACG AAT ATC TTT

70 Leu Tyr Val Ala Gly Phe Ile Asn Thr Glu Thr Asn Ile Phe Tyr Arg Phe Ser Asp Phe 80

$$
\text { Val Thr Thr }
$$

90

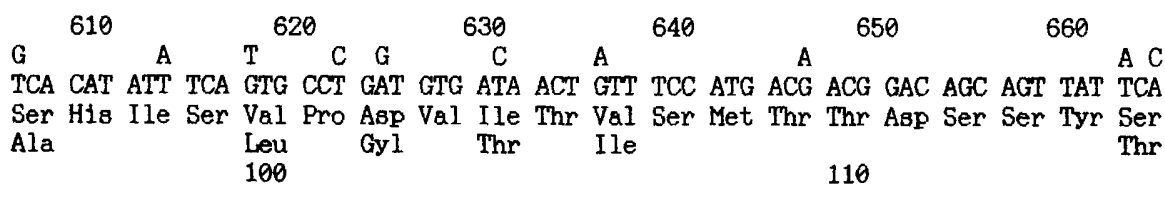
670
680
690
A T C G A T G ${ }^{680}$ CG $\quad 690$ T C A $\quad \begin{aligned} & 710 \\ & \text { C A T }\end{aligned}$
710
720 TCA TTA CAG CGA ATC GCA GAT CTG GAA CGT ACA GGG ATG CAG ATT GGG CGT CAT TCA CTG Ser Leu Gln Arg Ile Ala Asp Leu Glu Arg Thr Gly Met Gln Ile Gly Arg His Ser Leu Thr $\mathrm{Val}$
120 Ala Ser 130 Ser

$$
730
$$

TCA

740

750

760

770

$\begin{array}{r}780 \\ \hline\end{array}$

GTT GGT TCA TAT CTG GAT TTA ATG GAG TTC AGA GGA CGT TCC ATG ACC CGC GCA TCA TCC

Val Gly Ser Tyr Leu Asp Leu Met Glu Phe Arg Gly Arg Ser Met Thr Arg Ala Ser Ser Ser 140
Ser Asn Thr

150
Asp Ala 

790
800
810
820
C T A $\stackrel{830}{G}$
840

AGA GCT ATG CTG CGT TTT GTC ACA GTG ATA GCA GAA GCT CTG CGA TTC AGA CAA ATA CAG Arg Ala Met Leu Arg Phe Val Thr Val Ile Ala Glu Ala Leu Arg Phe Arg Gin Ile Gln $\mathrm{Val}$

160 Thr

170

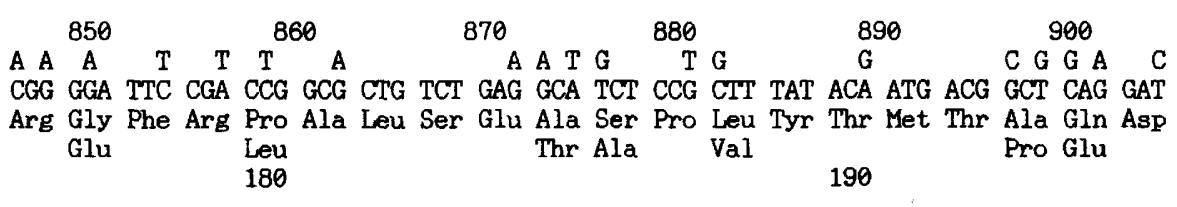

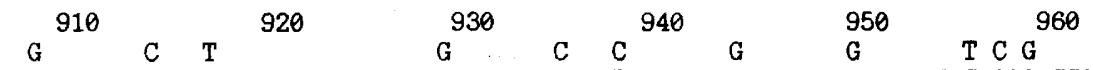

GTT GAC CTT ACC CTG AAC TGG GGA AGA ATA AGT AAT GTT CTT CCA GAG TAC AGA GGA GAG Val Asp Leu Thr Leu Asn Trp Gly Arg Ile Ser Asn Val Leu Pro Glu Tyr Arg Gly Glu

200

210

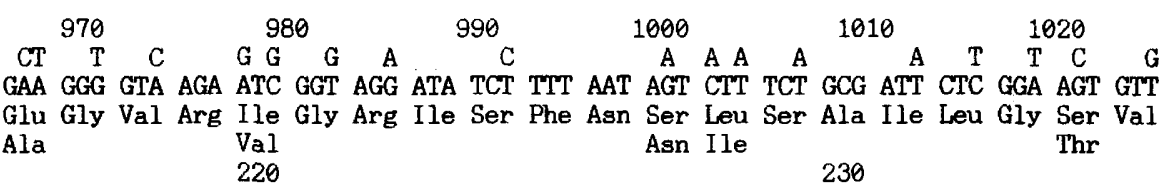

$\begin{array}{llllll}1030 & 1040 & 1050 & 1060 & 1070 & 1080\end{array}$

C $\mathrm{TAA}$ G + TA G GCG CG T A G AT G G G

GCG GTC ATC CTT AAT TGC CAC TCA ACC GGA AGT TAT TCA GTT CGT TCC GTG AGC CAA AAA Ala Val Ile Leu Asn Cys His Ser Thr Gly Ser Tyr Ser Val Arg Ser Val Ser Gln Lys $240 \quad$ His Gln Ala Arg 250 Ala Asn Glu Glu

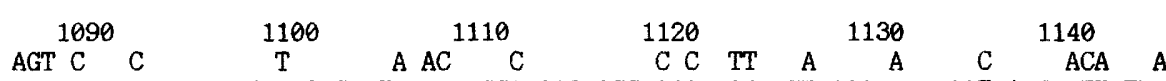
CAG AAA ACA GAA TGC CAG ATT GTT GGA GAC AGG GCG GCC ATT AAA GTA AAT AAT GTT TTG Gln Lys Thr Glu Cys Gln Ile Val Gly Asp Arg Ala Ala Ile Lys Val Asn Asn Val Leu

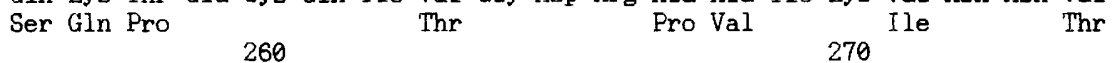

1150 AGT 1160 GCA A G T C G $_{\text {C A A }}^{1170}$ T A $\begin{array}{llllll}1190 & \text { TC T A TA AC A T }\end{array}$
TGG GAA GCG AAT ACA ATC GCT GCT TTA TTA AAT CGC AAG CCT CAG GAT CTT ACT GAA CCA Trp Glu Ala Asn Thr I le Ala Ala Leu Leu Asn Arg Lys Pro Gin Asp Leu Thr Glu Pro Ser Ala Phe Ser Ser Tyr Thr Thr 280 290 $\begin{array}{llllllllllllll}1210 & & 1220 & & 1230 & 1240 & & & 1250 & \text { T } & 1260 \\ \text { GGT G } & \text { G } & \text { A } & \text { A } & \text { T A } & \text { GA } & & & \text { T } & \text { A } & \text { G } & & \text { T } & \text { CA T G G }\end{array}$ AAC CAA TAA CAG GGG GTG AAT ATG AAG AAG ATG ATT ATT GCA GTT TTA TTC GGT CTC TTT Asn Gln SD Met Lys Lys Met Ile Ile Ala Val Leu Phe Gly Leu Phe Gly Glu $-19$

Phe

$1270 \quad 1280$

T G A AA 1300

TCT GCT AAT TCC ATG GCG GCG GAT TGT GCT GTA GGA AAA ATT GAG TTT TCC AAG TAT AAT Ser Ala Asn Ser Met Ala Ala Asp Cys Ala Val Gly Lys Ile Glu Phe Ser Lys Tyr Asn Val Ala $-1+1$ Lys $\begin{array}{lll}1330 & 1340 & 1350 \\ \text { A } & & \end{array}$

GAG GAT GAT ACC TIT ACT GTG AAG GTG TCA GGA AGA GAA TAC TGG ACG AAC AGA TGG AAT Glu Asp Asp Thr Phe Thr Val Lys Val Ser Gly Arg Glu Tyr Trp Thr Asn Arg Trp Asn Asn

20

30

$\begin{array}{llllll}1390 & 1400 & 1410 & 1420 & 1430 & 1440\end{array}$

TTG CAG CCA TTG TTA CAA AGT GCT CAG CTG ACA GGG ATG ACT GTA ACA ATC ATA TCT AAT Leu Gln Pro Leu Leu Gln Ser Ala Gln Leu Thr Gly Met Thr Val Thr Ile Ile Ser Asn 
ACC TGC AGT TCA GGC TCA GGC TTT GCC CAG GTG AAG TTT AAC TGAGAATCTACGGTTTATTTATGCG Thr Cys Ser Ser Gly Ser Gly Phe Ala Gln Val Lys Phe Asn

60

$\begin{array}{llllcccr}1520 & 1530 & 1540 & 1550 & 1560 & 1570 & 1580 & 1590 \\ (\mathrm{CT}) & & & & & & & \\ ++++++++++++++++++++\end{array}$

CGTCTTTTGTTCTGGACGCAGATATTATTAGTGTTGTGGATGCTGATTAAATTTGGTCAGTGTTTTCGTTAAATCATA

$\begin{array}{llllllll}1600 & 1610 & 1620 & 1630 & 1640 & 1650 & 1660 & 1670\end{array}$

$++++++++++++++t$

TAAATACAGGGCGICACGCCCCITTTTGGTCTGTAGTTGGGTGAAGATCATCACTTTACTTTGCTCAAATAACTCAGCA

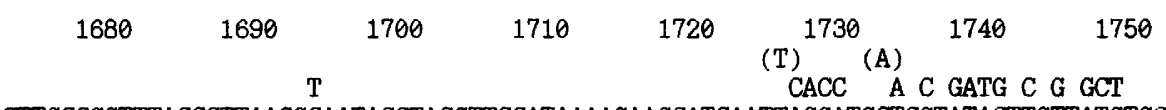

CTTGCCGGTTTACCCTTAAGGCAATACCTACGTTCCATAAAAGAAGCATCAATTAGGATGCTCGTATACTTGTTATGTGC

1760
GAGGGC G
TTTAAATGTT

Fig. 3. Nucleotide sequence of the sltIIva operon from E. coli strain H.I.8. Numbers above the sequence indicate the nucleotide position and those below the sequence the amino acid residue position. The open reading frame for the sitIIva A subunit structural gene extends from nucleotide positions 254 to 1210 and that for the B subunit structural gene from nucleotide positions 1226 to 1486 . The -35 and -10 regions of the proposed promoter are indicated. Shine-Dalgarno (SD) sequences are located upstream of the start codons for the respective $A$ and $B$ subunit sequences. Negative numbers are given to amino acids in the signal peptide while those in the processed polypeptides are positive. The proposed cleavage sites are located between amino acid residues -1 and +1 . The sequence is compared with the published sltIIv nucleotide sequence (Weinstein et al., 1988) from nucleotides 1 to 1715 of $s t$ IIV. In the comparison the DNA sequence $5^{\prime}$ to the initiation codon, the nucleotide and predicted amino acid sequence of structural genes for the A and B subunits, nucleotides in the gap between A and B subunits and the DNA sequence 3 ' to the termination codon of the gene for the B subunit were aligned separately with the corresponding regions of sitIIv. These data have been combined in the figure. Nucleotides from $s l t I I v$ which differ from those of sltIIva are placed above the sitIIva nucleotide sequence and amino acid residues which differ are placed below those of the sltIIva amino acid sequences. The plus signs above nucleotides indicate that they are present in slt IIVa but not in sltIIv and parentheses indicate nucleotides present in sltIIv but not in slt IIva. A putative rho-independent terminator is located from residues 1680 to 1706 ; the inverted repeat present in this region is underlined.

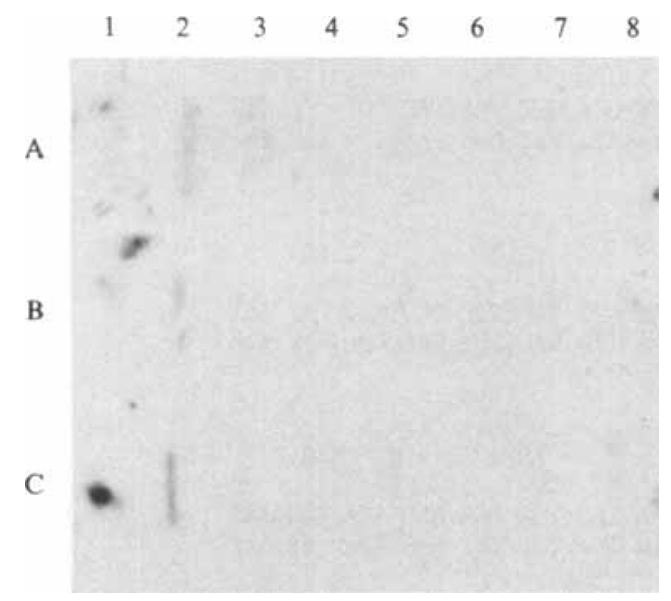

Fig. 4. Hybridization of oligonucleotide probes complementary to the sltIIva A subunit gene with total cellular DNA of $E$. coli strains. Total DNA (5 $\mu \mathrm{g}$ per slot) of $E$. coli strains was transferred to nylon membranes with a slot-blot apparatus. $E$. coli strains: 6600 slt $^{-}$ (positions 1 and 8), H.I.8 (O128:B12) sltIIva ${ }^{+}$(position 2), C600(933W) sltII+ (position 3), 412 (O139:K82) slt $\mathrm{IIv}^{+}$(position 4),
sltIIva A subunit DNA sequence to that of other slt genes. The three synthetic oligonucleotide DNA probes (5'-TGTCACAGTGATAGCAG-3', 5'-GGCCTTGATCCATATAG-3', and 5'-GTCTTCAGCATCTTATG-3') selected each hybridized under highly stringent conditions with total DNA from E. coli strain H.I. 8 but hybridized weakly or not at all with the total DNA from several other SLT-producing $E$. coli strains examined, including the $\mathrm{K} 12$ strain $\mathrm{C} 600(933 \mathrm{~W})(\mathrm{SLTII})$, human pathogens H19 (O26:H11)(SLTI), E32511 (O157:H-)(VT2) and B2F1/3 (O91:H21)(VT2) and an oedema disease strain 412 (O139:K82)(SLTIIv) (Fig. 4).

E32511 (O157:H7) vt2+ (position 5), B2F1/3 (O91:H21) $v t 2^{+}$(position 6) and $\mathrm{H} 19(\mathrm{O} 26: \mathrm{Hl})$ slt $\mathrm{I}^{+}$(position 7) are shown. Autoradiographs are shown of membranes which were hybridized with the following ${ }^{32} \mathrm{P}$-labelled oligonucleotide probes: 5'-TGTCACAGTGATAGCAG$3^{\prime}$ (A), 5'-GGCCTTGATCCATATAG-3' (B) and 5'-GTCTTCAGCATCTTATG-3' (C). 


\section{Discussion}

In the comparison of the nucleotide sequences of the four slt genes, areas of high homology of sltIIva with slt IIV were readily apparent. The close relationship was most obvious in the nucleotide sequence encoding the $B$ subunit and the region downstream of its termination codon. The interruption of this region of homology by a 38 nucleotide stretch in sltIIva suggests that recombination rather than simple base substitution has occurred in the evolution of these two toxin genes. The relationship among the regions encoding the $\mathrm{A}$ subunit and promoter region for the toxin genes is less clear and is more consistent with genetic divergence resulting from single base alterations.

Several reports in the literature suggest circumstances by which genetic recombination between sltIIva and slt IIv genes may have occurred. Firstly, the co-occurrence of SLT variants within single $E$. coli strains has been noted (Scotland et al., 1985; Strockbine et al., 1986) and provides the necessary situation for this event. In this regard, O'Brien et al. (1989) have recently suggested that homologous recombination between sit I and slt II or other bacteriophage genes may occur in $E$. coli strain 933(O157:H7). Genetic rearrangement such as this could clearly lead to variation in slt genes. Secondly, Kozlov et al. (1988) have reported that DNA with homology to an $E$. coli insertion sequence flanks the Shiga toxin gene of $S$. dysenteriae. Transposition may be another means by which gene transfer and recombination may have taken place in this toxin group.

Information from this study suggests that the sitIIva gene is located on the chromosome. Although we were unable to induce a bacteriophage or transfer VT from $E$. coli $\mathrm{H}$.I. 8 to $E$. coli $\mathrm{C} 600$, further study will be required to determine the nature of DNA sequences flanking the slt IIva gene.

While nucleotide sequence comparisons of $s l t \mathrm{I}$, slt II and $s l t I I v$ genes firmly establish differences among these genes, recent reports in the literature suggest that several additional types of SLT (VT) await characterization. Three $E$. coli strains which are reported to produce these toxins include E32511 (O157:H7) (Dickie et al., 1989), which produces the 'VT2' prototype (Scotland et al., 1985), B2F1/3 (O91:H21) (Oku et al., 1989) and H.I.8 (O128:B12) (Gannon \& Gyles, 1990). The DNA sequence data presented in this study support the contention that the SLT of E. coli strain H.I.8 does indeed represent a distinct type of the toxin. While we have previously shown that the VT of strain H.I.8 differs from other SLTs in heat lability and biological activity (Gannon \& Gyles, 1990), a comparison of the sltIIva with other slt genes had not been made at the nucleotide sequence level. We were particularly interest- ed in the relationship of sltIIva to slt genes from $E$. coli strains which may produce other types of SLT. In this study, three synthetic oligonucleotide DNA probes, complementary to the sitIIva A subunit gene, were used in hybridization studies to examine this relationship. Failure of these probes to hybridize strongly with DNA of other SLT-producing E. coli strains suggests that $s l t I I v a$ differs from the slt genes examined. However, this does not imply that sltIIva or toxins more closely related to it do not occur in other $E$. coli strains. A comparison of sltIIva with genes of other $O$ serogroup 128 E. coli strains, particularly those which fail to hybridize with VT1- or VT2-specific DNA probes (Smith et al., 1987), would be of interest.

SLTs and Shiga toxin A subunits have been shown to possess $\mathrm{N}$-glycosidase activity and inhibit protein synthesis by cleavage of the terminal portion of the $28 \mathrm{~S}$ ribosomal RNA subunit (Endo et al., 1988; Saxena et al., 1989). This mechanism of action is shared by plant toxins such as ricin (Endo et al., 1987). Homology of the amino acid sequence of the processed A subunit of SLTs with ricin A chain has been noted by several workers (De Grandis et al., 1987; Calderwood et al., 1987; Weinstein et al., 1988) and recently, Hovde et al. (1988) have demonstrated, with oligonucleotide-directed mutagenesis, that the glutamic acid residue at position 167 of SLTI is necessary for full enzymic activity of the toxin subunit. A number of common amino acids were noted from positions 165 to 206 of the processed SLTIIva A subunit and 175 to 215 of the ricin A chain (see Fig. 5). This includes the glutamic acid residue mentioned above as well as several additional residues which are common to SLTI, SLTII and ricin. These residues are thought to occur in the enzymically active site or 'cleft' of the ricin A chain.

Recent studies have shown that SLTI and SLTII bind specifically to globotriosylceramide (Waddell et al., 1988; Boyd \& Lingwood, 1989) and that SLTIIv binds with high affinity to globotetraosylceramide (De Grandis et al., 1989) and that these glycolipids, respectively, are probably the toxin receptors on cell surfaces. The high level of homology between the B subunits of SLTIIv and SLTIIva suggests that these toxins may have a common receptor which differs from that of SLTI and SLTII. This suggestion is supported by the low level of activity of SLTIIv and SLTIIva preparations against HeLa 229 cells relative to Vero cells. It will be of interest to see if differences in receptor specificity among SLTs result in different manifestations of disease in man and animals.

Finally, considerable debate exists with respect to the nomenclature of this group of $E$. coli toxins. Konowalchuk et al. (1977) first used the term 'Vero toxin' to describe the effects of certain $E$. coli broth culture 


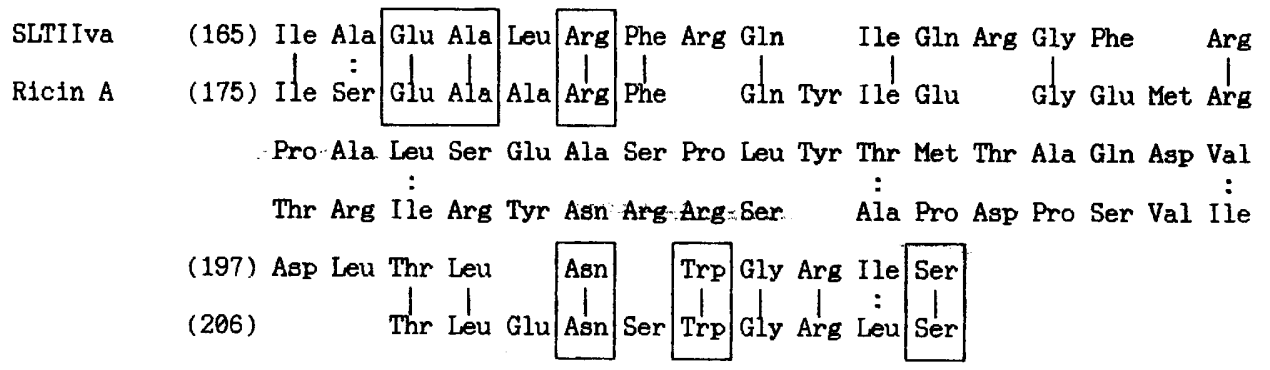

Fig. 5. A comparison of homologous amino acids in the A subunit of SLTIIva (positions 165-206) with the ricin A chain (positions 175215) was conducted using the MicroGenie alignment program. Solid vertical lines indicate identity; dots indicate conservative amino acid substitutions. Conserved amino acids in the cleft of the ricin A chain crystal structure are those reported by Hovde et al. (1988). These are boxed where agreement occurs between the A subunit of SLTIIva and the ricin A chain. Gaps were introduced into both sequences to maximize the alignment.

supernatants on Vero cells. Continued use of this term in the literature is presumably in recognition of these pioneering efforts. O'Brien et al. (1982) and others have employed the term 'shiga-like toxin' to describe this group of $E$. coli toxins because of their relationship to Shiga toxin. They argue that if historical precedent is to be followed, then Shiga's discovery of the related toxin from $S$. dysenteriae, prior to the turn of the century, should be the precedent. Our use of the term SLTIIva is intended to indicate the close relationship of the toxin of strain H.I.8 to SLTIIv and to allow for simple designation of other variants which may be characterized. Thus other variants could be called SLTIIvb, c, etc. When a single system of nomenclature is agreed on, it will be possible to rename toxins as appropriate.

Financial support for this study was provided by Agriculture Canada. We wish to thank Rita Bigham and Elaine Tanaka for technical assistance.

\section{References}

Ausubel, F. M., Brent, R., Kingston, R. E., Moore, D. D., Seidman, J. G., Smith, J. A. \& STrUHL, K. (editors) (1987). Current Protocols in Molecular Biology. New York: Greene Publishing Associates and Wiley-Interscience.

BIRNBoIM, H. C. \& Doly, J. (1979). A rapid alkaline extraction procedure for screening recombinant plasmid DNA. Nucleic Acids Research 7, 1513-1523.

BoYD, B. \& LINGWOOD, C. (1989). Verotoxin receptor glycolipid in human renal tissue. Nephron 51, 207-210.

BRENDEL, V. \& TRIFonov, E. N. (1984). A computer algorithm for testing potential prokaryotic terminators. Nucleic Acids Research 12 , 4411-4427.

Brown, J. I., Sethabutr, O., Jackson, M. P., Lolekha, S. \& ECHEVERRIA, P. (1989). Hybridization of Escherichia coli producing Shiga-like toxin I, Shiga-like toxin II and a variant of Shiga-like toxin II with synthetic oligonucleotide probes. Infection and Immunity 57, 2811-2814.

Calderwood, S. B., Auclair, F., Donohue-Rolfe, A., Keusch, G. T. \& MeKalanos, J. J. (1987). Nucleotide sequence of the Shigalike toxin genes of Escherichia coli. Proceedings of the National Academy of Sciences of the United States of America 84, 4364-4368.
De Grandis, S., Law, H., Brunton, J., Gyles, C. L. \& Lingwood, C. A. (1989). Globotetraosylceramide is recognized by the pig edema disease toxin. Journal of Biological Chemistry 264, 12520-12525.

De Grandis, S., Ginsberg, J., Toone, M., Climie, S., Friesen, J. \& BRUNTON, J. (1987). Nucleotide sequence and promoter mapping of the Escherichia coli shiga-like toxin operon of bacteriophage H-19B. Journal of Bacteriology 159, 4313-4319.

Dickie, N., SPeIRS, J. I., AKHTAR, M., Johnson, W. M. \& SZABo, R. A. (1989). Purification of an Escherichia coli serogroup O157:H7 verotoxin and its detection in North American hemorrhagic colitis isolates. Journal of Clinical Microbiology 27, 1973-1978.

Endo, Y., Mitsui, K., Mitzuki, M. \& Tsurugi, K. (1987). The mechanism of action of ricin and related toxic lectins on eukaryotic ribosomes. Journal of Biological Chemistry 257, 5908-5912.

Endo, Y., Tsuguri, K., Yutsudo, T., Takeda, Y., Ogasawara, T. \& IGARASH, K. (1988). The site of action of Verotoxin (VT2) from Escherichia coli $0157: \mathrm{H} 7$ and of Shiga toxin on eukaryotic ribosomes: $\mathrm{N}$-glycosidase activity of the toxins. European Journal of Biochemistry 171, 45-50.

Gannon, V. P. J. \& GYLES, C. L. (1990). Characteristics of the Shigalike toxin produced by Escherichia coli associated with porcine edema disease. Veterinary Microbiology (in the Press).

Gyles, C. L., De Grandis, S. A., Mackenzie, C. \& Brunton, J. L. (1988). Cloning and nucleotide sequence analysis of the genes determining Verocytotoxin production in a porcine edema disease isolate of Escherichia coli. Microbial Pathogenesis 5, 419-426.

voN HeIJNe, G. (1984). How do signal sequences maintain cleavage specificity? Journal of Molecular Biology 173, 243-251.

voN HeIJNE, G. (1985). Signal sequences: the limits of variation. Journal of Molecular Biology 184, 99-105.

HeNIKOFF, S. (1984). Unidirectional digestion with exonuclease III creates targeted breakpoints for DNA sequencing. Gene 28, 351-359.

HoHN, B. \& Collins, J. (1980). A small cosmid for efficient cloning of large DNA fragments. Gene 11, 291-298.

Holmes, D. S. \& QuigleY, M. (1981). A rapid boiling method for the preparation of bacterial plasmids. Analytical Biochemistry 114, 193196.

Hovde, C. J., Calderwood, S. B., Mekalanos, J. J. \& Collier, R. J. (1988). Evidence that glutamic acid 167 is an active-site residue of Shiga-like toxin I. Proceedings of the National Academy of Sciences of the United States of America 85, 2568-2572.

JaCkson, M. P., Neill, R. J. O'Brien, A. D., Holmes, R. K. \& NEWLAND, J. W. (1987a). Nucleotide sequence analysis and comparison of the structural genes for Shiga-like toxin I and Shigalike toxin II encoded by bacteriophages from Escherichia coli 933 . FEMS Microbiology Letters 44, 109-114.

JaCkson, M. P., Newland, J. W., Holmes, R. K. \& O'Brien, A. D. $(1987 b)$. Nucleotide sequence analysis of the structural genes for Shiga-like toxin I encoded by bacteriophage 933J from Escherichia coli. Microbial Pathogenesis 2, 147-153. 
KARCH, H. \& Bitzman, M. (1988). Purification and characterization of a phage-encoded cytotoxin from an Escherichia coli 0111 strain associated with hemolytic-uremic syndrome. Zentrablatt für Bakteriologie und Hygiene A270, 41-51.

KARCH, H. \& MEYERS, T. (1989). Evaluation of oligonucleotide probes for identification of shiga-like-toxin-producing Escherichia coli. Journal of Clinical Microbiology 27, 1180-1186.

Karmali, M. A., Petric, M., Lim, C., Fleming, P. C., Arbus, G. S. \& LIOR, H. (1985). The association between idiopathic hemolytic uremic syndrome and infection by verotoxin-producing Escherichia coli. Journal of Infectious Diseases 151, 775-782.

Konowalchux, J., Speirs, J. L. \& STaRvic, S. (1977). Vero response to a cytotoxin of Escherichia coli. Infection and Immunity 18, 775-779.

Kozlov, Y. V., Kabishev, A. A., Lukyanov, E. V. \& Bayer, A. A (1988). The primary structure of the operons coding for Shigella dysenteriae and temperate phage $\mathrm{H} 30$ shiga-like toxin. Gene 67, 213221 .

Maniatis, T., Fritsch, E. F. \& SambrooK, J. (1982). Molecular Cloning. A Laboratory Manual. Cold Spring Harbor, NY: Cold Spring Harbor Laboratory.

Marques, L. R. M., Peiris, J. S. M., Cryz, J. S. \& O'Brien, A. D (1987). Escherichia coli strains isolated from pigs with edema disease produce a variant of Shiga-like toxin II. FEMS Microbiology Letters 44, 33-38.

MCClURE, W. R. (1985). Mechanism and control of transcription initiation in prokaryotes. Annual Review of Biochemistry 54, 171204.

MORELle, G. (1989). A plasmid extraction procedure on a miniprep scale. Focus 11, 7-8.

Newland, J. W., Strockbine, N. A. \& Neill, R. J. (1987). Cloning of genes for production of Escherichia coli Shiga-like toxin type II Infection and Immunity 55, 2675-2680.

O'Brien, A. D. \& Holmes, R. K. (1987). Shiga and Shiga-like toxins. Microbiological Reviews 51, 206-220.

O'Brien, A. D., LAVECK, G. D., Thompson, M. R. \& Formal, S. B. (1982). Production of Shigella dysenteriae type 1-like cytotoxin by Escherichia coli. Journal of Infectious Diseases 146, 763-769.

O'Brien, A. D., Newland, J. W., Miller, S. F., Holmes, R. K., SMITH, H. W. \& Formal, S. B. (1984). Shiga-like toxin-converting phages from Escherichia coli strains that cause hemorrhagic colitis and infantile diarrhea. Science 226, 694-696.

O'Brien, A. D., Marques, L. R. M., Kerry, C. F., Newland, J. W. \& HolmEs, R. K. (1989). Shiga-like toxin converting phage of enterohemorrhagic Escherichia coli 933. Microbial Pathogenesis 6, 381-390.

OKu, Y., Yutsudo, T., HiRayama, T., O'Brien, A. D., Ogasawara, T. \& TAKEDA, T. (1989). Purification and some properties of a Vero toxin from a human strain of Escherichia coli that is immunologically related to Shiga-like toxin II (VT2). Microbial Pathogenesis 6, 113122.
Perera, L. P., Marques, L. R. M. \& O'Brien, A. D. (1988). Isolation and characterization of monoclonal antibodies to shiga-like toxin II of enterohemorrhagic Escherichia coli and the use of monoclonal antibodies in a colony enzyme-linked immunosorbent assay. Journal of Clinical Microbiology 22, 2127-2131.

SANGer, F., Nicklen, S. \& Coulson, A. R. (1977). DNA sequencing with chain-terminating inhibitors. Proceedings of the National Academy of Sciences of the United States of America 74, 5463-5467.

SAXena, S. K., O'Brien, A. D. \& ACKerman, E. J. (1989). Shigatoxin, Shiga-like toxin II variant, and ricin are all single-site RNA $N$ glycosidases of 28 S RNA when microinjected into Xenopus oocytes. Journal of Biological Chemistry 264, 596-601.

Scotland, S. M., SMITH, H. R. \& Rowe, B. (1985). Two distinct toxins active on Vero cells from Escherichia coli O157. Lancet 2, 885-886.

ShiNe, J. \& Dalgarno, L. (1974). The $3^{\prime}$ terminal sequences of Escherichia coli $16 \mathrm{~S}$ ribosomal RNA : complementarity of nonsense triplets and ribosomal binding sites. Proceedings of the National Academy of Sciences of the United States of America 71, 1342-1346.

SMITH, H. R. \& SCotland, S. M. (1988). Vero cytotoxin-producing strains of Escherichia coli. Journal of Medical Microbiology 26, 77-85.

Smith, H. R., Scotland, S. M., Chart, H. \& Rowe, B. (1987). Vero cytotoxin production and presence of VT genes in strains of Escherichia coli and Shigella. FEMS Microbiology Letters 42, 173177.

Smith, H. W., Green, P. \& Parsell, Z. (1983). Vero cell toxins in Escherichia coli and related bacteria: transfer by phage and conjugation and toxic action in laboratory animals, chickens and pigs. Journal of General Microbiology 129, 3121-3137.

Strockbine, N. A., Marques, L. R. M., Newland, J. W., Smith, H. W. Holmes, R. K. \& O'BRIEN, A. D. (1986). Two toxinconverting phages from Escherichia coli $\mathrm{O} 157: \mathrm{H} 7$ strain 933 encode antigenically distinct toxins with similar biological activity. Infection and Immunity 53, 135-140.

Strockbine, N. A., JACkson, M. P., Sung, L. M., Holmes, R. K. \& O'Brien, A. D. (1988). Cloning and sequencing of the genes for Shiga toxin from Shigella dysenteriae type 1. Journal of Bacteriology 170, 1116-1122.

VIEIRA, J. \& Messing, J. (1982). The pUC plasmids, an M13mp7derived system for insertional mutagenesis and sequencing with synthetic universal primers. Gene 19, 259-268.

Waddell, T., Head, S. C., Petric, M., Cohen, A., \& Lingwood, C. (1988). Globotriosyl ceramide is specifically recognized by the Escherichia coli verocytotoxin 2. Biochemical and Biophysical Research Communications 152, 674-679.

Weinstein, D. L., Jackson, M. P., Samuel, J. E., Holmes, R. K. \& O'BrIEN, A. D. (1988). Cloning and sequencing of a shiga-like toxin type II variant from an Escherichia coli strain responsible for edema disease of swine. Journal of Bacteriology 170, 4223-4230.

Yanisch-Perron, C., Vieira, J. \& Messing, J. (1985). Improved M13 phage cloning vectors and host strains: nucleotide sequences of the M13mp18 and pUC19 vectors. Gene 33, 103-119. 